\title{
Skiers On a Mountainside
}

\author{
Mrs. Ona F. Lick, Davidson
}

B LI Z Z A R D upon blizzard, last winter, in quick succession made life tough for man, bird and beast. Drifts grew bigger and bigger around buildings, in slough willows, around stacks and on roads. Trails made one day were obliterated the next. Farmers began taking shovels in sleighs to dig out their horses in case they became bogged down in drifts. Stubble fields were filled with snow, and possible gleanings of frozen wheat were covered. Cattle no longer could find sufficient food for even a half-decent subsistence. Horses left off their pawing. It is no wonder that game birds found living difficult, and sought food near to farm dwellings.

To our great surprise, one morning, we saw

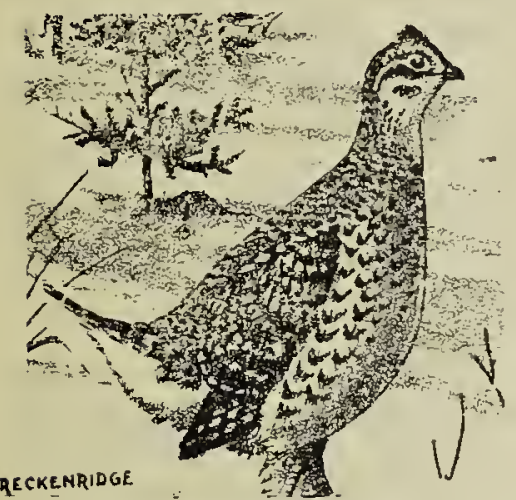
thirteen big birds in one row on our honeysuckle bushes, that is, in the portions of shrubs that showed above the drifts. They were Sharp-tailed Grouse, colloquially known as "Prairie Chickens," and were eating the abundant berries. It was amusing to see their big bodies swaying in the slender branches, and to see them jump for berries from the top of a drift.

We conceived the idea of coaxing them closer to the house by scattering wheat on the drifts-each evening a little nearer, and finally right beneath the windows on the strip of ground which the circling winds had swept fairly clean of snow. Beyond this strip was a four-foot snow embankment. It was fun to see them every morning, sharp at seven, start from the slough and run to their feeding ground as fast as their little snow-shoed feet would carry them. Often we thought they enjoyed sliding down the drift, just as much as the children did.

Nor were the grouse the only proteges. Several coveys of Hungarian Partridges fed out of the pan-a pan full of wheat was a subsequent addition Rabbits, too, came nightly to partake of the hand-out. Freshly fallen snow at night would be covered with grouse and partridge tracks by morning. The partridges were bolder than the grouse, fed sooner out of a pan, and often drove the timid grouse away.

Watching the "Prairie Chickens" on the further drifts was fascinating. In the caragana windbreak the drifts were high and jagged. Often a flock of grouse would come to the peak of one drift, run down it, one after another and up the next drift. They seemed to be skiers, sliding down a mountainside with sufficient momentum to carry them half-way up the next.

\section{BIRDS AT SPRUCE DALE FARM}

\section{Stuart, Francis}

$\mathbf{T}$ HE Whistling Swan which we obtained last fall is now completely recovered in health and is full of pep. It seems quite contented along with the wild geese. We are looking forward to spring, when we will have the pleasure of seeing this most beautiful bird at his best, swimming on a pond of freshly melted snow water, with the warm spring sun shining down, and the Killdeers and Mallards, the Goldeneye and Teal, coming and going from the pond. We look forward also to our own Canada Geese and Snow Goose indulging in the luxury of sleeping in the sun on the bank, after being confined to a building for five months.

Last year we recorded 79 species of migratory birds on our farm and in the district nearby. Several other species were seen but we were unable to identify them.

The flock of Ruffed Grouse are with us again this winter. Ten birds are to be seen in early morn and late afternoon around the barn and sheaf stacks. They just keep out of our way enough, so we will not step on them when carrying in feed. We all get a lot of fun out of watching them every day. The dog ruis among them and they pay no attention to him. 